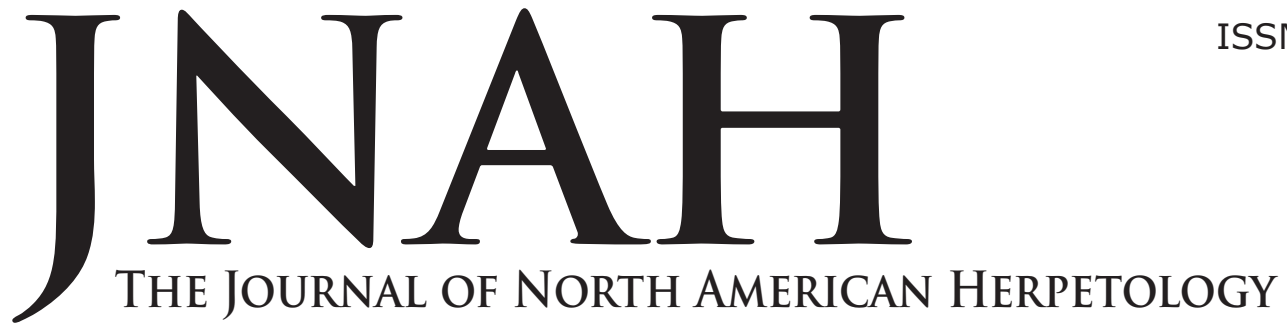

ISSN 2333-0694

Volume 2020, Number 1

23 March 2020

journals.ku.edu/jnah

\title{
ISOMETRY OF EGG SIZE IN A TEXAS POPULATION OF THE TURTLE STERNOTHERUS ODORATUS THAT EXHIBITS A NEARLY FIXED CLUTCH SIZE
}

\author{
PETER V. LINDEMAN \\ Department of Biology and Health Sciences, \\ Edinboro University of Pennsylvania, \\ 230 Scotland Road, Edinboro, PA 16444
}

plindeman@edinboro.edu

\begin{abstract}
In evaluating optimal egg-size theory and the effects of anatomical constraints on egg size in turtles, pivotal questions concern the significance of the relationship of egg size to female body size and whether the relationship is isometric or hypoallometric. In a central Texas population of the kinosternid turtle Sternotherus odoratus in which clutch size of a sample of turtles was nearly fixed (seven of eight females had two eggs while the largest female had three eggs), there was an isometric increase in egg width with body size among the females with two-egg clutches and significantly reduced egg width in the largest female's three-egg clutch. Allometric analyses of populations that exhibit little variation in clutch size, as well as analysis of modal clutch sizes in populations with more variable clutch sizes, both have the potential to further illuminate the competing demands of increasing egg size vs. increasing clutch size as females grow larger, enabling them to optimize their reproductive output as it increases with body size.
\end{abstract}

Key Words: Reproductive allometry; Reproductive output; Egg size; Optimal egg-size theory; South Llano River

\section{INTRODUCTION}

Studies of the reproductive ecology of turtles often evaluate competing hypotheses regarding the optimization of egg size vs. anatomical constraints that limit egg size in smaller adult females. Classic egg-size theory (Smith and Fretwell 1974, Brockelman 1975) predicts that as adult females grow larger, there is little fitness gained by increasing egg size, thus an increase in reproductive output is attained by increasing clutch size instead. The expectation of this model for turtles is that clutch size and clutch mass will increase with female size but there will be no correlation of egg size with female size (Congdon and Gibbons 1987, Ryan and Lindeman 2007). On the other hand, anatomical features of female turtles through which the eggs must pass, such as the width or height of the pelvic opening or the caudal gap between the carapace and plastron, may limit egg size, such that larger females not only produce more eggs, but also larger eggs (Tucker et al. 1978, Congdon and Gibbons 1987, Lindeman 2005, Ryan and Lindeman 2007). The limitation of egg size need not apply over the full range of body sizes, but may instead apply to only a subset of the smallest females in a population (DePari 1988, Rollinson and Brooks 2008, Lovich et al. 2012).
Allometric analysis, based on log-log regressions and evaluation of the confidence intervals on slopes, is a key technique for analyzing the relative increase in clutch size vs. increase in egg size as females grow to larger body sizes (Lindeman 2005, Ryan and Lindeman 2007, Lovich et al. 2012, Macip-Ríos et al. 2012, Naimi et al. 2012, Kern et al. 2016, Fehrenbach et al. 2016). Loglog transformation in an analysis of the correlation of reproductive variables with female body size not only enables direct comparison among studies of different species or among different populations within a single species, it also allows for evaluation of whether reproductive variables scale with increases in female body size hypoallometrically (i.e., increasing more slowly than body size does) or isometrically (increasing at the same rate as body size; King 2000). For regression of volumetric measurements on linear measurements (e.g., clutch size, clutch mass, or egg mass regressed on female shell length), the expectation under isometry of increase in the measurements would be a log-log slope of 3 (King 2000). For regression of linear measurements on linear measurements (e.g., egg width, pelvic aperture width or height, or caudal gap regressed on female shell length), the expectation under isometry would be a log-log slope 
of 1 . For regression of linear measurements on volumetric measurement (e.g., egg width, pelvic aperture width or height, or caudal gap width regressed on female body mass), the expectation under isometry would be a loglog slope of 0.33 .

The most common result in allometric analyses of reproductive output for freshwater turtles is that clutch size and egg size both scale hypoallometrically, which has been interpreted as evidence that they represent competing sinks for the increased reproductive output made possible by the greater abdominal space afforded by increasing body size (Lindeman 2005, Ryan and Lindeman 2007, Macip-Ríos et al. 2012, Naimi et al. 2012, Fehrenbach et al. 2016). Similar results with slopes well below isometric expectations, albeit without assessment of whether they were actually hypoallometric or isometric, have been reported in other studies (MacCulloch and Weller 1988, Rasmussen and Litzgus 2010, Rothermel and Castellón 2014). Additionally, for two populations of the turtle species Malaclemys terrapin, neither log-transformed clutch size nor log-transformed mean egg width was significantly correlated with log-transformed female plastron length, although both trended positively in the manner of the other studies; slopes of the relationships were likewise not reported or evaluated for isometry vs. allometry (Kern et al. 2016). An alternative pattern, with an approximately isometric relationship of clutch size with body size and no significant increase in egg width in larger females-consistent with the hypothesis of optimized egg size-has also been reported (Lovich et al. 2012). The pattern of dual hypoallometry may be the more common pattern in oviparous non-avian reptiles. Slopes yielded in interspecific analyses for turtles and non-avian reptiles in general also indicate dual hypoallometry of clutch size and egg size in their relationships to maternal size (Iverson 1992, Blueweiss et al. 1978; see discussion of both in Ryan and Lindeman 2007).

In the present study, I evaluate increases in egg width with increasing body size for a southern population of the small kinosternid turtle Sternotherus odoratus. Whereas clutch size varies greatly across the range of the species (1-13 eggs; Ernst and Lovich 2009), in my study population, clutch size appears to be nearly fixed, at two eggs. The advantage of this situation is that it largely removes the complicating influence of clutch-size variation on the allotment of energy to offspring provisioning. My analyses of seven two-egg clutches show an isometric increase in egg size that is also evident in analyses that include, and statistically correct for, a single three-egg clutch recorded for the largest female in the sample.

\section{METHODS}

I captured S. odoratus in the South Llano River in the vicinity of two crossings of Hwy. 377 near the town of Telegraph in Kimble County, Texas, in mid-May in 1998 and 1999 and in early June in 2000. The South Llano River is a cool, spring-fed river with swift currents in short, shallow, rocky riffle zones alternating with deeper, slower pools with muddy or rocky substrates. Captures were made in fykenets or occasionally via hand capture of turtles resting on the river bottom or basking near the riverbank, incidental to studies focused on the turtle species Graptemys versa and Pseudemys texana (Lindeman 2003, 2005, 2006, 2007).

I measured body size to the nearest $1 \mathrm{~mm}$ as straightline carapace length (SCL) using calipers held along the midline of the carapace. During the 1999 season, females determined to be gravid via inguinal palpation were radiographed (Gibbons and Greene 1979) at a local hospital and released at their sites of capture. I determined clutch size (CS), X-ray egg width (XREW), and pelvic aperture width (PAW) from each radiograph with correction for enlargement or reduction of XREW and PAW via reference to the image made by a coin of known diameter placed on the turtle's plastron (Graham and Petokas 1989).

I log-transformed all measurements in order to conduct analyses of allometry, via regression of mean and maximum XREW of a clutch and PAW on female SCL. I analyzed these relationships a) for the subset of females having the modal clutch size of two eggs, b) for all females, and c) in a model for all females that included a dummy variable representing the two clutch sizes ( $1=$ 2 eggs, $0=3$ eggs). I categorized relationships as isometric if the $95 \%$ confidence interval spanned the slope value expected under isometry (1.00) or hypoallometric if its upper bound was less than the expected slope.

\section{RESULTS}

Female S. odoratus ranged from $66-93 \mathrm{~mm} \mathrm{SCL}$ (mean $81.9 \mathrm{~mm}, \mathrm{SE}=0.93 \mathrm{~mm}, n=41$ ) and were similar in size to males (range 62-102 $\mathrm{mm} \mathrm{SCL}$, mean 83.1 $\mathrm{mm}, \mathrm{SE}=1.77 \mathrm{~mm}, n=31$ ) and to the sample of gravid females radiographed in 1999 (Figure 1). Of eight radiographed females, the smallest seven (range 76-86 mm $\mathrm{SCL}$, mean $81.9 \mathrm{~mm} \mathrm{SCL}$ ) each had two eggs, while the largest ( $90 \mathrm{~mm} \mathrm{SCL}$ ) had three eggs.

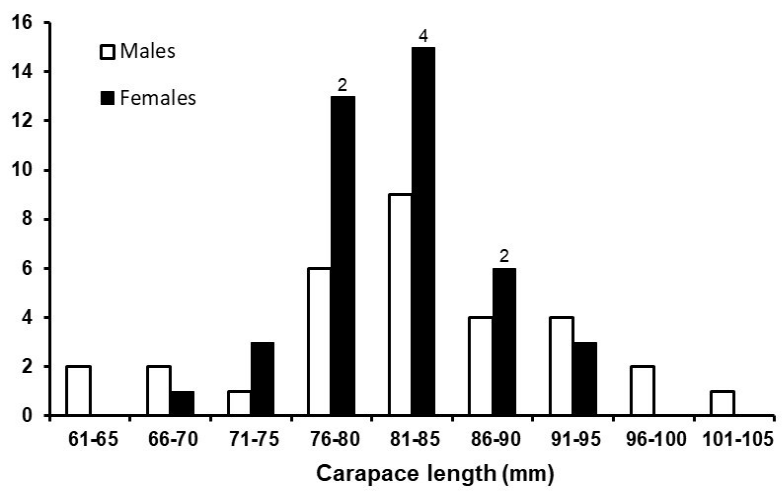

Figure 1. Histogram of straight-line carapace lengths of Sternotherus odoratus from the South Llano River, Kimble County, Texas. Numbers of radiographed gravid individuals are indicated above female bars.

For the eight radiographed females, mean and maximum XREW increased significantly with SCL (both $p<$ 0.03 ), while the relationship of PAW to SCL approached significance $(p=0.12)$. Similar results were obtained when analysis was confined to the seven females with two-egg clutches ( $p<0.01$ for both mean and maximum XREW, $p=0.078$ for PAW). For the seven females with two-egg clutches, slopes of the regression of mean and maximum XREW on SCL were very close to 1 and did not depart from isometry (Figure $2 \mathrm{~A}$ ). With the largest female and her three-egg clutch added to the data set, slopes were considerably less than 1 , although wide confidence intervals precluded finding them to be significant departures from isometry (Figure 2B). The scaling of PAW with SCL also did not depart significantly from isometry, with or without the largest female (Figure 2). 

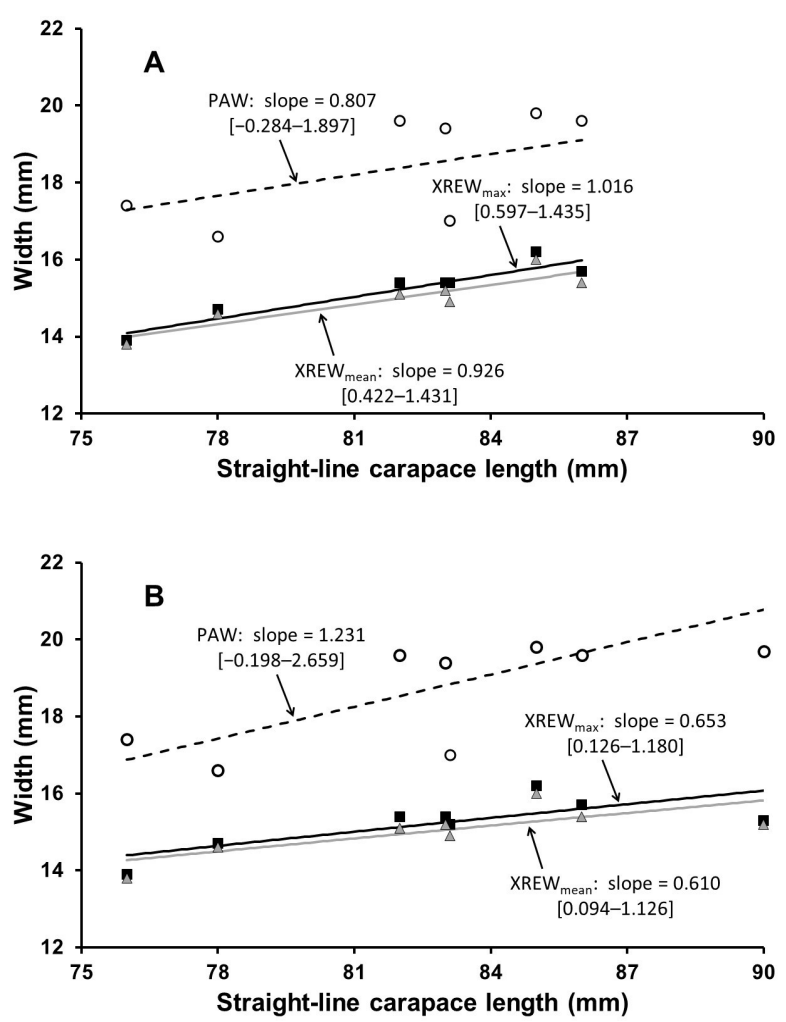

Figure 2. Relationships (based on log-log regressions, shown here back-transformed to the raw data) of pelvic aperture width (PAW, open circles and dashed line), maximum X-ray egg width (XREW ${ }_{\text {In }}$ ) in a clutch (black squares and solid line), and mean $X$-ray egg width $\left(X R E W_{\text {mean }}\right.$ ) in a clutch (gray triangles and solid line) for Sternotherus odoratus from the South Llano River, Kimble County, Texas. A) Analyses confined to a subset of seven females that had clutches of two eggs $\left(r^{2}=0.90, p=0.0052\right.$ for XREW mean $; r^{2}=0.94, p=0.0016$ for XREW max $; r^{2}=0.50, p$ $=0.078$ for PAW). B) Analyses including a large female with a three-egg clutch $\left(r^{2}=0.78, p=0.023\right.$ for $\mathrm{XREW}_{\text {mean }} ; r^{2}=0.76, p$ $=0.028$ for XREW ${ }_{\text {max }} ; r^{2}=0.35, p=0.12$ for PAW). Below each log-log slope are its $95 \%$ confidence intervals in brackets.

In a model relating XREW to SCL for all eight females with clutch size coded as a dummy variable $(1=$ modal clutch size of two eggs, $0=$ clutch size of three eggs), slopes reverted to being very close to 1 , were significantly different from zero $\left(p=0.0053\right.$ for $\mathrm{XREW}_{\text {mean }} ; p$ $=0.0016$ for $\left.X R E W_{\text {max }}\right)$, and did not depart from isometry based on their 95\% confidence intervals (Figure 3 ). Model terms for the clutch-size dummy variable indicated significantly smaller XREW for the single female that produced a three-egg clutch, as corrected for female size (for $\mathrm{XREW}_{\text {mean }}$, a 1.08-mm increase in width in two-egg vs. three-egg clutches; $t=2.58, p=0.049$; for XREW max' $^{\prime}$ a $1.09-\mathrm{mm}$ increase in width in two-egg vs. three-egg clutches; $t=3.51, p=0.017$ ).

\section{DISCUSSION}

Sternotherus odoratus ranges from Maine to Wisconsin to Texas to Florida (Ernst and Lovich 2009). Rangewide, its clutch size varies from 1-13 eggs, with population means ranging from 1.8-6.7, and clutch size and body size both increase with latitude (Tinkle 1961; Ernst 1986; Clark et al. 2001, Ewert 2005, Tucker and Lamer 2005). Clutch sizes in the South Llano River are thus among the smallest reported, undoubtedly because body sizes are also very small in this very southern portion of the species' range (compare data of the present study to data from "isotherm 70-75," the southernmost part of the range, in Tinkle 1961).

In spite of small sample size in the present study, the fit of models to isometric expectations (slope of 1 ) is striking for models involving only the seven two-egg clutches as well as models with the clutch-size dummy variable. Both analyses remove the influence of clutchsize variation on egg width, by ignoring the rare deviation in clutch size (Figure 2A) or including it with a statistical correction (Figure 3 ). In this way, the present analyses reinforce the interpretation of earlier studies that simultaneous hypoallometry of clutch size and egg width occurs because they represent competing sinks for increased reproductive output in larger females (Lindeman 2005, Ryan and Lindeman 2007, Macip-Ríos et al. 2012, Naimi et al. 2012, Fehrenbach et al. 2016), because in a population that exhibits little variation in one variable (clutch size), the other (egg width) scaled isometrically with female size.

My results appear to contrast with two previous analyses of egg-size optimization in populations of Sternotherus odoratus with more variable clutch sizes. In three Indiana populations, egg width appeared to be anatomically constrained, albeit more by the size of the female's caudal gap formed by her carapace and plastron than by the width of the pelvic aperture, and both clutch size (means 3.2-6.7 eggs, total $n=70$ ) and egg width increased with increasing female body size; there was no analysis of isometry vs. hypoallometry in the relationships, however (Clark et al. 2001). In a South Carolina population in which 46 clutches averaged 5.0 eggs and ranged from 2-8 eggs, both clutch size and egg width increased with female body size (Gibbons et al. 1982, Wilkinson and Gibbons 2005). Because egg width increased more slowly than pelvic aperture width did, the result is suggestive of hypoallometry of egg width (and probably dual hypoallometry of egg width and clutch size); however, the analyses were unfortunately not done with log-log transformation of variables.

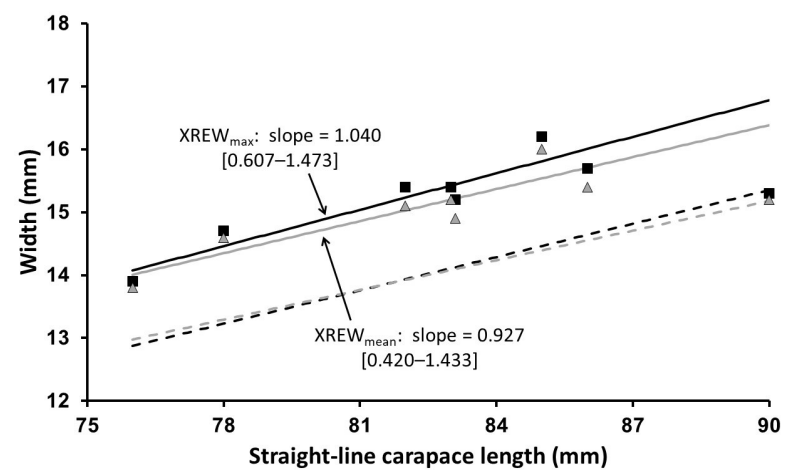

Figure 3. Relationships (based on log-log regressions, shown here back-transformed to the raw data, in a model for which clutch size was represented by a dummy variable coded as two eggs = 1 and three eggs $=0$ ) of maximum X-ray egg width (XREW ${ }_{\text {max }}$ black lines and squares) per clutch and mean X-ray egg width (XREW, gray lines and triangles) per clutch, for Sternotherus odoratus from the South Llano River, Kimble County, Texas. Solid lines represent predicted egg widths of two-egg clutches, while their parallel dashed lines represent predicted reduction in egg width for three-egg clutches. Below each log-log slope are its $95 \%$ confidence intervals in brackets. Model $R^{2}$ values were 0.82 for $\mathrm{XREW}_{\text {mean }}$ and 0.88 for $\mathrm{XREW}_{\text {max }}$ 
Fixed or nearly fixed clutch size occurs in some turtle populations: several small-bodied South African testudinid species have clutch sizes typically of one or, in some cases, rarely two (Hofmeyr et al. 2005); in a small-bodied population of the emydid Graptemys sabinensis from the upper Calcasieu River, 23 of 30 clutches consisted of two eggs (Ewert et al. 2004, Fehrenbach et al. 2016); and many geoemydid species have small and nearly invariant clutch sizes (e.g., Chen and Lue 1999, Innis 2003, Whitaker and Vijaya 2009). In the testudinid Homopus signatus, which typically lays a single egg, egg width and pelvic aperture width increased with female carapace length with nearly identical log-log slopes (0.69 and 0.70, respectively; Hofmeyr et al. 2005). Additional studies should examine the expectation of an isometric increase in egg size in other species with fixed or nearly fixed clutch size. Similarly, in a turtle population in which egg size is optimized and thus unrelated to female size, the expectation is of an isometric increase in clutch size as female body size increases. Lovich et al. (2012) presented a case in the kinosternid turtle Kinosternon sonoriense that seems to fit the latter scenario.

Along a continuum of the influence that female body size has on reproductive parameters in turtles, opposite extremes are represented by relatively invariant clutch size (state $i$ in Figure 4) and egg width variation that is not related to female body size (state iv in Figure 4). In between these extremes are states in which turtles have variable clutch sizes and in which ii) body size constrains egg width across the complete range of female body sizes, as optimal egg size is not achievable within that range of body sizes; or iii) body size constrains egg size in smaller females but not in larger females, such
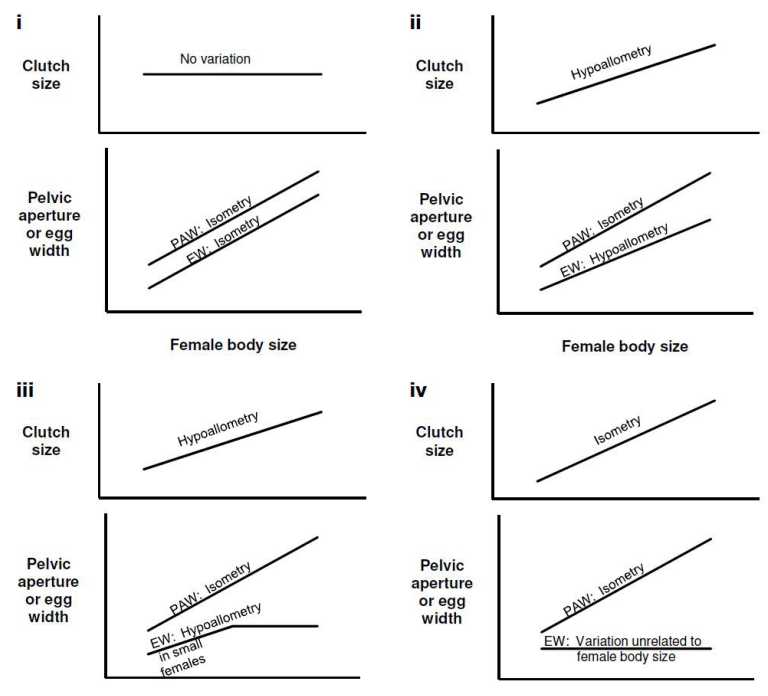

Female body size

Female body size

Figure 4. A continuum of body-size relationships with clutch size and egg width in turtles: i) isometric increase of egg width in a population with no variation in clutch size, ii) hypoallometric relationships of both clutch size and egg width with female body size across the full range of female body sizes, iii) hypoallometric relationships of clutch size and egg width with female body sizes at small sizes, with egg width showing no body-size relationship as it becomes optimized when anatomical constraints are eased in larger females, and iv) isometric relationship of clutch size with female body size and no body-size related variation in egg width in species in which all females are large enough for egg size to be optimized. that while both clutch size and egg width scale hypoallometrically with female size, the latter tapers off as it increases, as larger females are freed from the anatomical constraints that prohibit smaller females from producing eggs of an optimal size.

Future allometric studies of anatomical constraints on egg width in turtles should further investigate methods of analysis that account for the simultaneous influences of increasing body size and variation in clutch size on egg size. Separate analyses of isometry in egg size that isolate well-represented modal clutch sizes (as with the two-egg clutches of the present study; Figure 2A) and inclusion of dummy variables to correct for clutch-size variation in complete data sets (Figure 3 ) show promise for achieving this objective.

Acknowledgments - I thank T. Allen, L. Arkwright, D. Edwards, J. Lovell, and L. Lovell for their able assistance in the field and the Kimble County Hospital for radiographing turtles. The manuscript was read by J. Ennen, $\mathrm{J}$. Iverson, and N. Rollinson, who made several helpful comments. Field work was partially supported by Madisonville Community College and was conducted under Texas Scientific Permit Number SPR-0297-864.

\section{LITERATURE CITED}

Blueweiss, L., H. Fox, V. Kudzma, D. Nakashima, R. Peters, and S. Sams. 1978. Relationships between body size and some life history parameters. Oecologica 37:257-272.

Brockelman, W.Y. 1975. Competition, the fitness of offspring, and optimal clutch size. American Naturalist 109:677-699.

Chen, T.-H., and K.-Y. Lue. 1999. Population characteristics and egg production of the yellow-margined box turtle, Cuora flavomarginata flavomarginata, in northern Taiwan. Herpetologica 55:487-498.

Clark, P.J., M.A. Ewert, and C.E. Nelson. 2001. Physical apertures as constraints on egg size and shape in the common musk turtle, Sternotherus odoratus. Functional Ecology 15:70-77.

Congdon, J.D., and J.W. Gibbons. 1987. Morphological constraints on egg size: a challenge to optimal egg size theory? Proceedings of the National Academy of Sciences USA 84:4145-4147.

DePari, J.A. 1988. Overwintering in the Nest Chamber by Hatchling Painted Turtles, Chrysemys picta, in Northern New Jersey. Ph.D. Dissertation, Rutgers University, USA.

Ernst, C.H. 1986. Ecology of the turtle, Sternotherus odoratus, in southeastern Pennsylvania. Journal of Herpetology 20:341-352.

Ernst, C.H., and J.E. Lovich. 2009. Turtles of the United States and Canada, $2^{\text {nd }}$ ed. The Johns Hopkins University Press, USA.

Ewert, M.A. 2005. Sternotherus odoratus (common musk turtle). Size and reproduction. Herpetological Review 36:314.

Ewert, M.A., J.S. Doody, and J.L. Carr. 2004. Graptemys ouachitensis sabinensis (Sabine map turtle). Reproduction. Herpetological Review 35:382-383.

Fehrenbach, A.K., I. Louque, S.L. McFadden, C. Huntzinger, E. Lyons, S.H. Shively, W. Selman, and P.V. Lindeman. 2016. Habitat-related variation in body size and reproductive output and an examination of reproductive allometry in the Sabine map turtle (Graptemys sabinensis) across three river drainages. Copeia 104:458-468. 
Gibbons, J.W., and J.L. Greene. 1979. X-ray photography: a technique to determine reproductive patterns of freshwater turtles. Herpetologica 35:86-89.

Gibbons, J.W., J.L. Greene, and K.K. Patterson. 1982. Variation in reproductive characteristics of aquatic turtles. Copeia 1982:776-784.

Graham, T.E., and P.J. Petokas. 1989. Correcting for magnification when taking measurements directly from radiographs. Herpetological Review 20:46-47.

Hofmeyr, M.D., B.T. Henen, and V.J.T. Loehr. 2005. Overcoming environmental and morphological constraints: egg size and pelvic kinesis in the smallest tortoise, Homopus signatus. Canadian Journal of Zoology 83:1343-1352.

Innis, C.J. 2003. Preliminary observations on reproductive parameters of the Sulawesi forest turtle (Leucocephalon yuwonoi) in captivity. Chelonian Conservation and Biology 4:720-721.

Iverson, J.B. 1992. Correlates of reproductive output in turtles (order Testudines). Herpetological Monographs $6: 25-42$.

Kern, M.M., J.C. Guzy, J.E. Lovich, J.W. Gibbons, and M.E. Dorcas. 2016. Relationships of maternal body size and morphology with egg and clutch size in the diamondback terrapin, Malaclemys terrapin (Testudines: Emydidae). Biological Journal of the Linnean Society 117:295-304.

King, R.B. 2000. Analyzing the relationship between clutch size and female body size in reptiles. Journal of Herpetology 34:148-150.

Lindeman, P.V. 2003. Sexual difference in habitat use of Texas map turtles (Emydidae: Graptemys versa) and its relationship to size dimorphism and dietary differences. Canadian Journal of Zoology 81:1185-1191.

Lindeman, P.V. 2005. Aspects of the life history of the Texas map turtle (Graptemys versa). American Midland Naturalist 153:378-388.

Lindeman, P.V. 2006. Diet of the Texas map turtle (Graptemys versa): relationship to sexually-dimorphic trophic morphology and changes over five decades as influenced by an invasive mollusk. Chelonian Conservation and Biology 5:25-31.

Lindeman, P.V. 2007. Diet, growth, body size, and reproductive potential of the Texas river cooter (Pseudemys texana). Southwestern Naturalist 52:586-594.

Lovich, J.E., S.V. Madrak, C.A. Drost, A.J. Monatesti, D. Casper, and M. Znari. 2012. Optimal egg size in a suboptimal environment: reproductive ecology of female Sonora mud turtles (Kinosternon sonoriense) in central Arizona, USA. Amphibia-Reptilia 33:161-170.
Macip-Ríos, R., P. Brauer-Robleda, G. Casas-Andreu, M.d.L. Arias-Cisneros, and V.H. Sustaita-Rodríguez. 2012. Evidence for the morphological constraint hypothesis and optimal offspring size theory in the Mexican mud turtle (Kinosternon integrum). Zoological Science 29:60-65.

MacCulloch, R.D., and W.F. Weller. 1988. Some aspects of reproduction in a Lake Erie population of Blanding's turtle, Emydoidea blandingii. Canadian Journal of Zoology 66:2317-2319.

Naimi, M., M. Znari, J.E. Lovich, Y. Feddadi, and M.A.A. Baamrane. 2012. Clutch and egg allometry of the turtle Mauremys leprosa (Chelonia: Geoemydidae) from a polluted peri-urban river in west-central Morocco. Herpetological Journal 22:43-49.

Rasmussen, M.L., and J.D. Litzgus. 2010. Patterns of maternal investment in spotted turtles (Clemmys guttata): implications of trade-offs, scales of analyses, and incubation substrates. Écoscience 17:47-58.

Rollinson, N., and R.J. Brooks. 2008. Optimal offspring provisioning when egg size is "constrained": a case study with the painted turtle Chrysemys picta. Oikos $117: 144-151$

Rothermel, B.B., and T.D. Castellón. 2014. Factors influencing reproductive output and egg size in a southern population of gopher tortoises. Southeastern Naturalist 13:705-720.

Ryan, K.M., and P.V. Lindeman. 2007. Reproductive allometry in the common map turtle, Graptemys geographica. American Midland Naturalist 158:49-59.

Smith, C.C., and D. Fretwell. 1974. The optimal balance between size and number of offspring. American Naturalist 108:499-506.

Tinkle, D.W. 1961. Geographic variation in reproduction, size, sex ratio and maturity of Sternothaerus odoratus (Testudinata: Chelydridae). Ecology 42:68-76.

Tucker, J.K., and J.T. Lamer. 2005. Sternotherus odoratus (common musk turtle). Clutch size. Herpetological Review 36:314.

Tucker, J.K., R.S. Funk, and G.L. Paukstis. 1978. The adaptive significance of egg morphology in two turtles (Chrysemys picta and Terrapene carolina). Bulletin of the Maryland Herpetological Society 14:10-22.

Whitaker, N., and J. Vijaya. 2009. Biology of the forest cane turtle, Vijayachelys silvatica, in South India. CheIonian Conservation and Biology 8:109-115.

Wilkinson, L.R., and J.W. Gibbons. 2005. Patterns of reproductive allocation: clutch and egg size variation in three freshwater turtles. Copeia 2005:868-879. 